\title{
Towards a New Platform Based on Learning Outcomes Analysis for Mobile Serious Games
}

\author{
https://doi.org/10.3991/ijet.v15i02.11637 \\ Elaachak Lotfi \\ University Abdelmalek Essaadi, Tangier, Morocco \\ lotfil002@gmail.com
}

\begin{abstract}
Nowadays, learning via smartphones has become one of the most popular teaching tools used by young people, thanks to the ease of use of such devices in the field of education. There are now a large number of both instructional applications and mobile serious games "MSGs" which are available in mobile applications stores. The diversity of such applications especially MSGs can guarantee a personalized learning experience for each learner. However, it is difficult to decide if a given MSG is efficient or not because this decision depends on several factors. One of those major factors is their ability to transmit knowledge effectively to the learners, in order to teach them new skills. This ability can be measured and then analyzed by using several techniques and algorithms like learning analytics, educational data mining, inference knowledge e.g. "Bayesian Knowledge Tracing", etc. Hence the need for the establishment of a user-friendly platform based on these algorithms, the proposed platform will be able to evaluate easily the learning outcomes of this kind of video games.
\end{abstract}

Keywords-Mobile, serious games, learning analytics, educational data mining, knowledge inference.

\section{Introduction}

Since the eighties, many of traditional teaching manners have been replaced by new ones, which are based essentially on information technologies, where devices such computers and smartphones play an important role to transmit knowledge to several categories of learners [1]. The main advantage of using smartphones in education is their ability to allow learners to learn anywhere and at any time [2].

Serious games [3, 4] which are among these new teaching tools and in the same time they can be run in smartphones through the use of cross-platform game engines [5, 6, and 7] during their development process, have known a huge success this last decade thanks to their capacity to offer both interactive and enjoyable learning experience and allow learners to acquire new skills.

Despite the success of mobile serious games [8], there is the main problem in how to prove their effectiveness, the most common method usually used in this case is based on learners' feedbacks $[9,10]$, but it is not efficient for measuring learning ef- 
fectiveness through this kind of video games. However, looking in the literature there are several techniques and algorithms that can be used for analyzing learning outcomes e.g. "Learning analytics [11], Educational data mining [12, 13, 14], knowledge inference "Bayesian Knowledge Tracing" [15], etc.", all of these techniques can be helpful for experts/instructors to evaluate mobile serious games on the pedagogical side and especially their abilities to transmit knowledge to the novice learners.

In this perspective of research we will present in this paper a novel learning outcomes analysis platform for mobile serious games, the proposed platform contains a set of data mining, learning analysis, and inference knowledge algorithms, with a friendly user interface including several features e.g. "data visualization, prediction, rules extraction, and statistics summary".

\section{Theoretical Background}

\subsection{Mobile serious games}

Mobile serious games "MSGs" are new kind of serious games [3, 4], which are designed to run on smartphones, with the main objective to educate, train, and inform novice learners in an amused way. They are becoming a key element in the development of serious games by integrated them into the real world through the use of several resources of mobile devices e.g. "camera, GPS, gyroscope, etc", therefore, many MSGs have been developed over the past few years by several researchers/experts in different fields, Table 1 below shows some MSGs.

Table 1. Some MSGs from different fields

\begin{tabular}{|l|l|l|}
\hline \multicolumn{1}{|c|}{ Name } & \multicolumn{1}{|c|}{ Field } & \multicolumn{1}{c|}{ Description } \\
\hline Utopolis [16] & History & $\begin{array}{l}\text { The addresses and simulates a democracy, it accompanied by } \\
\text { a short film aiming at remembering the Holocaust to young } \\
\text { people in a media format. }\end{array}$ \\
\hline OOP Serious game [17] & $\begin{array}{l}\text { The idea behind the game is to introduce the basics of Object } \\
\text { Oriented Programming paradigms e.g. "object, class, inher- } \\
\text { itance, polymorphism, etc", by using animals in the zoo } \\
\text { context. }\end{array}$ \\
\hline Medialis [18] & Healthcare & $\begin{array}{l}\text { Medialis has been developed to train decision making, diag- } \\
\text { nosis, and management of biliary tract disease. }\end{array}$ \\
\hline Dr. Game: Surgeon Trouble [19] & Healthcare & $\begin{array}{l}\text { The game is designed for medical experts in the objective } \\
\text { situational awareness and troubleshooting skills for surgical } \\
\text { doctors, surgeons, and other operating room staff }\end{array}$ \\
\hline
\end{tabular}

In general, all the realizations found in the literature have one main objective, which is transmitting knowledge easily to the learners, and benefit from all the features and technologies offered by mobile devices. 


\subsection{Learning analytics educational data mining and Bayesian knowledge tracing}

The most known definition of learning analytics was given by the Society for Learning Analytics Research (SOLAR). Learning analytics is "the measurement, collection, analysis, and reporting of data about learners and their contexts, for purposes of understanding and optimizing learning and the environments in which it occurs" [20]. It is considered as in disciplinary field between data science, pedagogy, instructional technologies, machine learning, probability and statistics [21, 22]. The essential role of learning analytics is to use educational data to improve learning and learning environments [23]. Learning analytics uses predictive models. It is a multidisciplinary approach based on data processing, technology-learning enhancement, educational data mining, and data visualization [24].

Educational data mining "EDM" [25, 26] is a subfield of data mining; it focuses on developing methods with an objective of promoting discoveries from data in the educational field. It finds and examines patterns in a large data set related to learners' behaviors and actions. The methods may be utilized to better understand the educational settings and learners. The obtained knowledge from EDM can be used to improve learners' performances, understand learners' behaviors, to assist instructors, to improve teaching process, and to construct predictive models to predict students' performances in terms of learning progression [27], EDM algorithms and methods may also be used to categorize the students who require support, to analyze students' learning and cluster them according to their strengths and weaknesses for placement related activities.

Bayesian Knowledge Tracing [15], is a user modeling method used in the area of intelligent tutoring systems, the algorithm behind BTK is an estimation algorithm that has been applied in several studies [28,29] to model the student learning process. Especially the study about Knowledge Tracing and Prediction of Future Trainee Performance [30], that discusses the possibilities of using the Bayesian approach to predict student performances and steer training process to enhance learning objectives. The BTK models are composed of four parameters: "P(L0), P(T), P(S), P(G)", and they are usually fit using the expectation maximization method (EM) [31], Conjugate Gradient Search [15], or discretized brute-force search [32].

$\mathrm{P}\left(\mathrm{L}_{0}\right)$ : (p-init) initial probability of knowing the skill a priori.

$\mathrm{P}(\mathrm{T})$ : (p-transit) probability of learner's knowledge of a skill transitioning from not known to the known state.

$\mathrm{P}(\mathrm{S})$ : (p-slip) probability to make a mistake when applying a known skill.

$\mathrm{P}(\mathrm{G})$ : (p- guess) probability of correctly applying a not-known skill.

The formulas used to update learner knowledge of skills are as follows. The initial probability of learner L mastering skill " $\mathrm{S}$ " is set to the (p-init) parameter for that skill Equation (1). Depending on whether the learner "L" applied skill "S" correctly or incorrectly, the conditional probability is computed either using Equation (2) or (3). The conditional probability is used to update the probability of skill mastery according to Equation (4). To compute the probability of learner L applying the skill "S" correctly on an upcoming practice opportunity one uses Equation (5). 


$$
\begin{gathered}
P\left(L_{1}\right)_{u}^{k}=P\left(L_{0}\right)^{k} \\
P\left(L_{t+1} \vee \text { obs }=\text { correct }\right)_{u}^{k}=\frac{P\left(L_{t}\right)_{u}^{k} \cdot\left(1-P(S)^{k}\right)}{P\left(L_{t}\right)_{u}^{k} \cdot\left(1-P\left(S^{k}\right)+\left(1-P\left(L_{t}\right)_{u}^{k}\right) \cdot P(G)^{k}\right.} \\
P\left(L_{t+1} \vee \text { obs }=\text { wrong }\right)_{u}^{k}=\frac{P\left(L_{t}\right)_{u}^{k} P(S)^{k}}{P\left(L_{t}\right)_{u}^{k} \cdot P(S)^{k}+\left(1-P\left(L_{t}\right)_{u}^{k}\right) \cdot(1-P(G) \mid k)} \\
P\left(L_{t+1}\right)_{u}^{k}=P\left(L_{t+1} \vee o b s\right)_{u}^{k}+\left(1-P\left(L_{t+1} \vee o b s\right) \mid u^{k}\right) \cdot P(T)^{k} \\
P\left(C_{t+1}\right)_{u}^{k}=P\left(L_{t}\right)_{u}^{k}+\left(1-P(S) \mid u^{k}\right)+\left(1-P\left(L_{t}\right) \mid u^{k}\right) \cdot P(G)^{k}
\end{gathered}
$$

All methods and machine learning algorithms described below in Table 2 will be

\begin{tabular}{|c|c|}
\hline Algorithms & Application \\
\hline $\begin{array}{l}\text { "Decision tree, SVM, Artificial neural network, KNN, } \\
\text { Naïve Bays, etc" [33] }\end{array}$ & $\begin{array}{l}\text { Data mining/machine Learning/supervised learn- } \\
\text { ing/prediction models }\end{array}$ \\
\hline "K-means, EM, PCA, etc"[34, 35 and 36] & $\begin{array}{l}\text { Data mining/machine Learning /Unsupervised } \\
\text { Learning /Clustering/ Dimensionality reduction }\end{array}$ \\
\hline Association rules learning [37] & Data mining/ rule-based machine learning \\
\hline Bayesian Knowledge Tracing [17] & Intelligent tutoring systems \\
\hline
\end{tabular}
integrated into the proposed platform; this variety of algorithms will offer to the experts/instructors several opportunities to analyze learning outcomes of their learners that learn through mobile serious games.

Table 2. Algorithms and their applications

\subsection{LA and EDM platforms/frameworks}

Several frameworks and platforms have been developed until today, by several researchers, institutions, and computer science laboratories, the main aim of these realizations is both analyzing and understanding learners' behaviors, in order to give each learner a personalized learning process that meets his need and allow him to improve his abilities to acquire more skills.

OPENET4VE [38], a learning analytics framework for 3D educational virtual words, the framework has been developed by B. Fernández et al, OPENET4VE is an OpenSim-based virtual world platform and it is compliant with the IMS Learning Design specification and it has the ability of monitoring and registering the events generated by both learners and instructors. Based on these event logs, process mining algorithms automatically extract the real learning flow of the course, allowing instructors to introduce changes in the learning flow initially proposed.

Ioannis Kazanidis et al [39] have proposed in their paper a platform for data mining in E-learning, the platform is based on a framework for recording, processing and analyzing data from Learning Management Systems (LMS). Its purpose and functionalities are to facilitate teachers towards the achievement of course efficiency, and also the improvements of course content are based on learners' behaviors from data mining techniques over LMS data. 
Hiroaki OGATA et al [40], have developed a Learning Evidence Analytics Framework, which is a technological design framework to support the evidence-based education system. The framework is composed of several components based on the model of data-driven activities, data collection, and analysis supported by both LA engine that does the statistical computation and LA View which is a dashboard for visualizing the indicators.

There are others realizations [41, 42, 43, and 44] found in the literature, each one has its pros and cons, by cons the majority of them are dedicated for E-learning environments instead of to be dedicated for serious games/mobile serious games. In addition, there is a lack of platforms/frameworks that combine Learning Analytics, Educational data mining and inference knowledge algorithms and techniques in one software solution to analyze learning outcomes.

\section{$3 \quad$ Method}

The learning outcomes analysis platform is a web-based platform that allows the data visualization, learning analytics, educational data mining and inference knowledge of data collected from several mobile serious games. Among the main objectives of this platform is helping instructors and teachers to have a global view on the learning progression of their students in order to understand more their behaviors and their abilities to acquire new skills.

The proposed platform was developed by using several new web technologies including single page application concept [45] and service-oriented architecture based on REST [46, 47]. There is also a smart layer developed by using several APIs e.g. "weka [48]" or developed from scratch, to build prediction models, and allow the inference knowledge analysis, and finally, it is equipped by a dashboard based on a variety of tools for data visualization.

\subsection{Platform for learning outcomes analysis}

The platform process is composed of several steps see Fig. 1, it begins by loading a log file into the platform, which must be XML, JSON or CSV format with several attributes inside, the second step of the process consists of setting the attributes of the loaded file according to the chosen features and classes, during the third step the user can view data, generate prediction models, do clustering, finally he can also use both association rules and inference knowledge algorithms to extract new learning patterns or verify if the pedagogical objectives have been transmitted efficiently to the learners. 


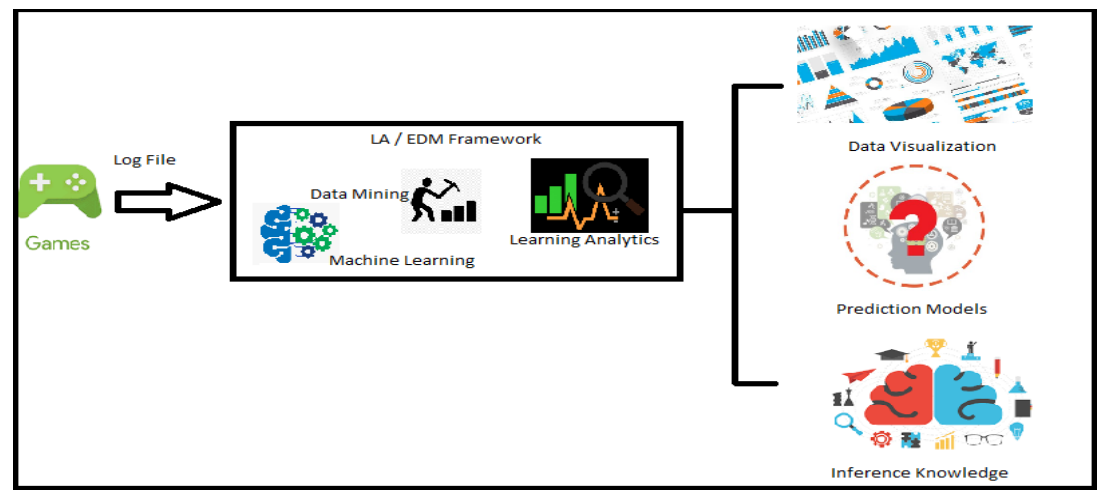

Fig. 1. Learning outcomes analysis process via the platform

\subsection{Platform architecture}

The proposed platform is designed according to multi-layers architecture see Figure 2, where each layer has a specific role during the analysis process. There are three main layers: Data source layer, EDM/LA Layer and Process Layer.

- Data source layer: The main role of this layer is to save different types of flux e.g. "CSV, XML, JSON, etc.", loaded from different log files of mobile serious games, into several structured data sources e.g." Databases, NoSql, files, etc.".

- EDM/LA layer: This layer contents several modules of learning analytics, machine learning, inference knowledge, and data mining algorithms. These modules have been developed either using the third party services provider or from scratch.

- Process layer: Many APIs have been used in this layer for data cleaning, data visualization, file loading, and data mapping, this layer has direct a link to the web user interface.

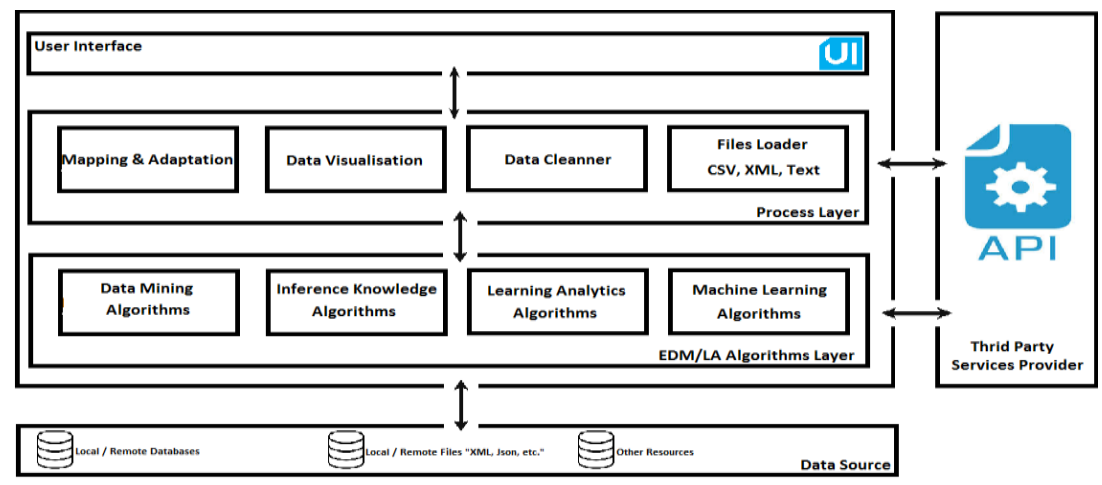

Fig. 2. Learning outcomes analysis process via the platform 


\subsection{OOP Mobile Serious game and ELISA Mobile Serious Game: The case study}

During this case study, we will use tow mobile serious games: Object-oriented programming mobile serious game and ELISA mobile serious game, which have been developed by our research team, each mobile game has its proper log file that will be treated over the proposed platform.

The OOP mobile serious game [17], is a serious game that teaches basics of objectoriented programming paradigms e.g." class, object, inheritance, and polymorphism", the game is composed of four main levels see Figure 3, it was inspired from the zoo world and it is based on drag and drop gameplay.

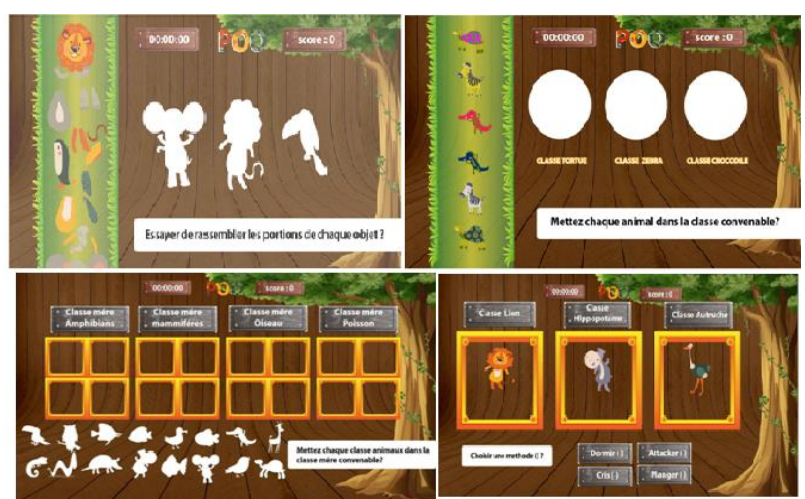

Fig. 3. Learning outcomes analysis process via the platform

ELISA mobile serious game [49], is a serious game which has been developed by our research team ELISA. The Game provides a virtual laboratory for students of biology/immunology to develop their practices of immunological technics by playing. The learner must pass with success 12 steps of the game to complete the process of the ELISA method.

The main pedagogical objectives of ELISA mobile serious game are:

- Understand the principle of ELISA

- Highlight the interest of antibodies as a diagnostic tool

- Understand the principle of ELISA method in the detection of AIDS

- Describe the different steps of the method

- Identify the main characteristic of an antibody

- Know the structure of HIV 


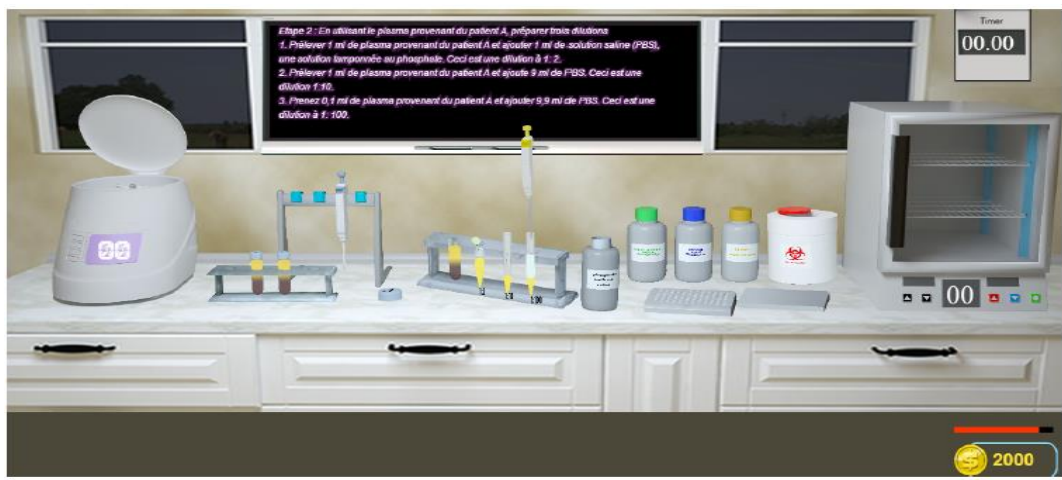

Fig. 4. Learning outcomes analysis process via the platform

\section{$4 \quad$ Results and Discussion}

The proposed platform was developed by using several web technologies and frameworks already mentioned above e.g. "REST, Spring, Javascript APIs, etc." Its main objective is analyzing, inferencing, visualizing data collected from mobile serious games, then interpreting theme by using both machine learning algorithms and inference knowledge technics to create different models to predict and understand learner's behaviors, then give the instructors a global view concerning the progression of their students.

Several experimentations concerning the learning outcomes analysis through the proposed platform have been applied on different learners who tried to play mobile serious games which were developed by our research team, already mentioned in the section above e.g."OOP mobiles serious game and ELISA mobile serious game". The main objective of such experimentations was testing both integrity and efficiency of the platform in different manners including process fluidity, setting, data visualization, perdition models, inference knowledge models, ergonomics, etc.

During the process of analysis via the platform, the user should pass by several steps, at the beginning which is a preparation step, where the user can fill all the information about the project e.g 'project name, pedagogical objectives, game levels, game genre, etc". Then he can upload "Fig. 7" a Log file which is a CSV file, with header, body and comma separator see Fig. 5. The platform will automatically map the file with different tables in the database, established from the class diagram "Fig. 6". 


\begin{tabular}{c|c|c|c|c|c|c|} 
Name & date & Time & score & énergie barre (\%) & phases & 1omber of tries \\
\hline aghmir nisrine & $26 / 12 / 201621: 52$ & $0: 20: 12$ & 4600 & 77 & 3 & 3 \\
\hline bouazza yasmine & $19 / 12 / 201622: 35$ & $0: 00: 20$ & 800 & 100 & 1 & 1 \\
\hline Boukili Soumia & $24 / 12 / 201619: 58$ & $0: 00: 20$ & 800 & 100 & 1 & 1 \\
\hline haj haddou sirine & $30 / 12 / 201617: 57$ & $6: 39: 22$ & 2800 & 94 & 2 & 1 \\
\hline KALLAT Omaima & $26 / 12 / 201620: 58$ & $0: 00: 20$ & 800 & 100 & 1 & 1 \\
\hline Khaoula el amrani el idrissi & $24 / 12 / 201622: 29$ & $0: 00: 20$ & 800 & 100 & 1 & 1 \\
\hline KONE ZAHINAB & $19 / 12 / 201623: 03$ & $0: 00: 20$ & 800 & 100 & 1 & 1 \\
\hline Manal & $19 / 12 / 201622: 57$ & $0: 09: 23$ & 2800 & 94 & 2 & 2 \\
\hline mousliks salma & $26 / 12 / 201621: 00$ & $0: 00: 20$ & 800 & 100 & 1 & 1 \\
\hline nambinina & $20 / 12 / 20168: 11$ & $0: 00: 20$ & 800 & 100 & 1 & 1 \\
\hline saandat mohamed mze & $20 / 12 / 201619: 22$ & $0: 21: 28$ & 5600 & 48 & 5 & 8 \\
\hline saandat mouhamed & $19 / 12 / 201622: 19$ & $0: 00: 20$ & 800 & 100 & 1 & 1 \\
\hline Samadi rogaya & $26 / 12 / 201622: 02$ & $0: 00: 20$ & 800 & 100 & 1 & 1 \\
\hline SITTI HILMA MOHAMED & $20 / 12 / 20160: 22$ & $0: 05: 08$ & 2800 & 94 & 2 & 2
\end{tabular}

Fig. 5. Log file of ELISA Mobile Serious Game

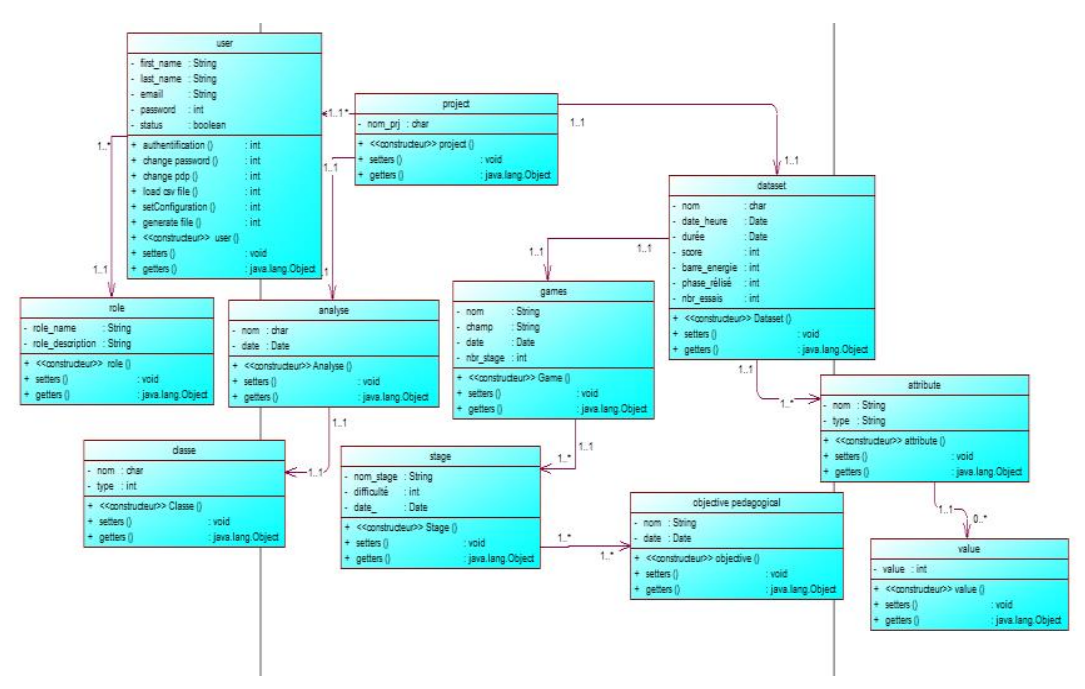

Fig. 6. Class Diagram of the Platform

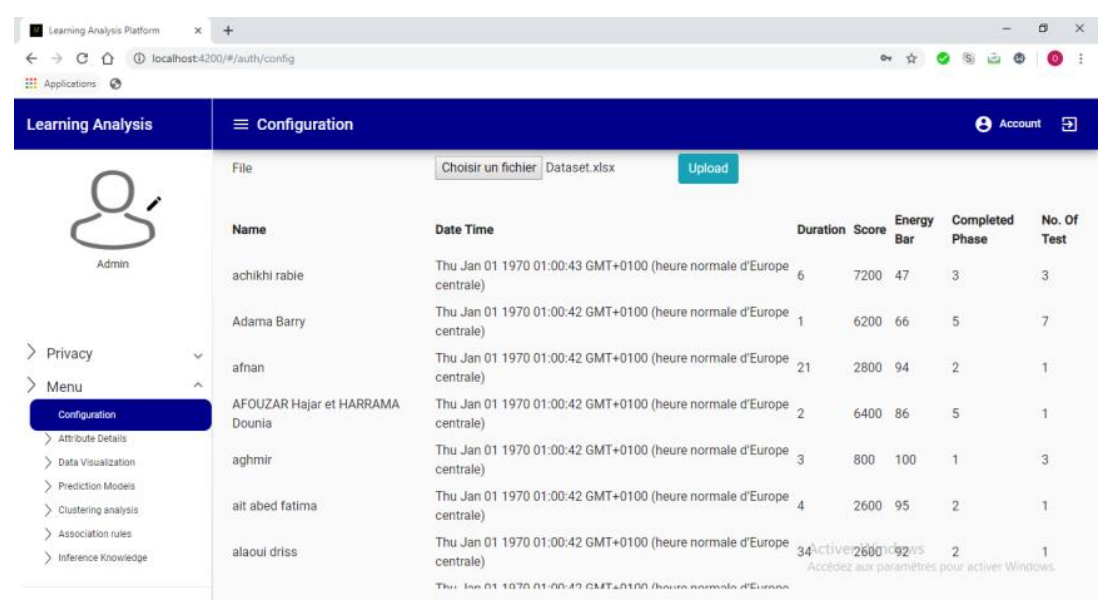

Fig. 7. File loading and mapping according to database tables 
The second step consists on both setting and mapping of the attributes already saved in the database, during this step the user must choose the attributes that will be as features, and the attribute that will be class for the predictive and inference knowledge models, see Figure 8.

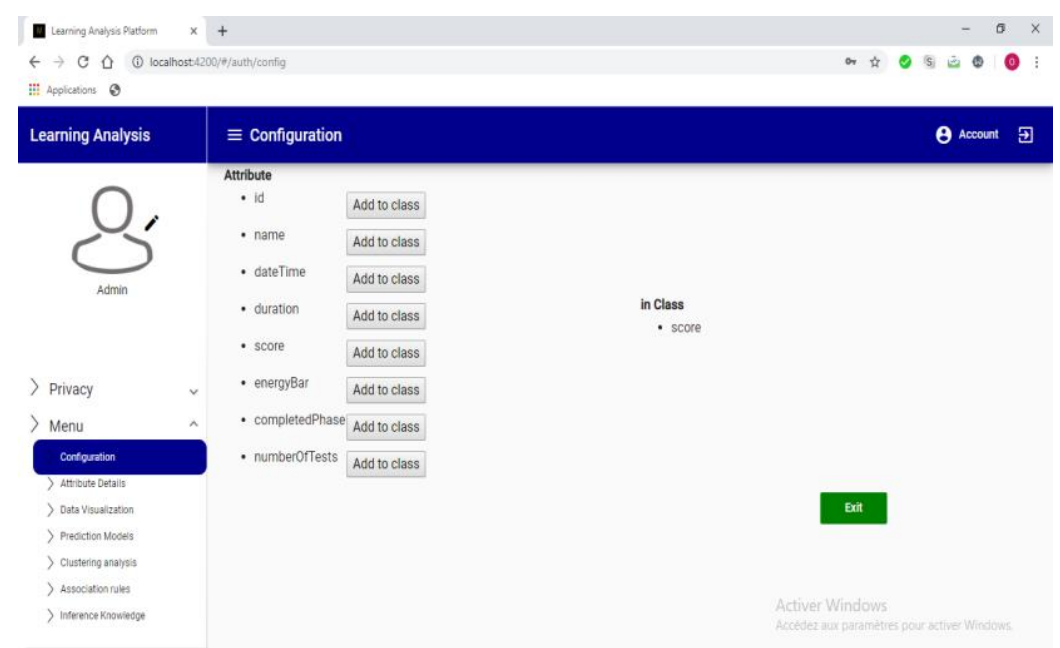

Fig. 8. Settings of the attributes according to features and class

After setting phase, the user can visualize data through the use of several charts e.g "bar chart, pie chart, etc", the visualization concerns the data and the attributes retrieved from the log file, during this step the user can switch dynamically between attributes in order, to visualize different statistical presentation based on several charts and related to the two attributes chosen by him, see Figure 9. He can also get the statistical summary of the data loaded Figure 10.

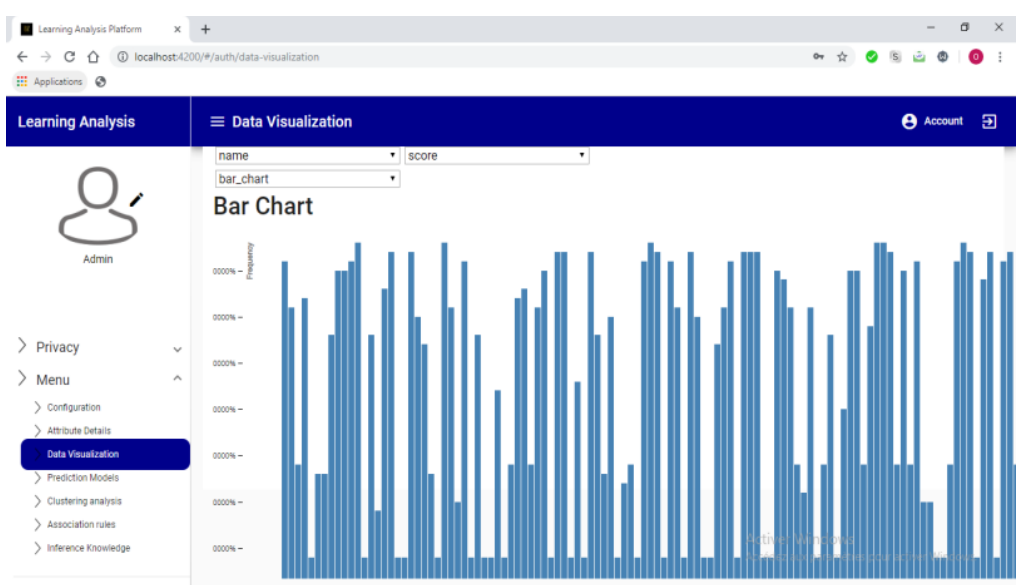

Fig. 9. Data Visualization of attributes 


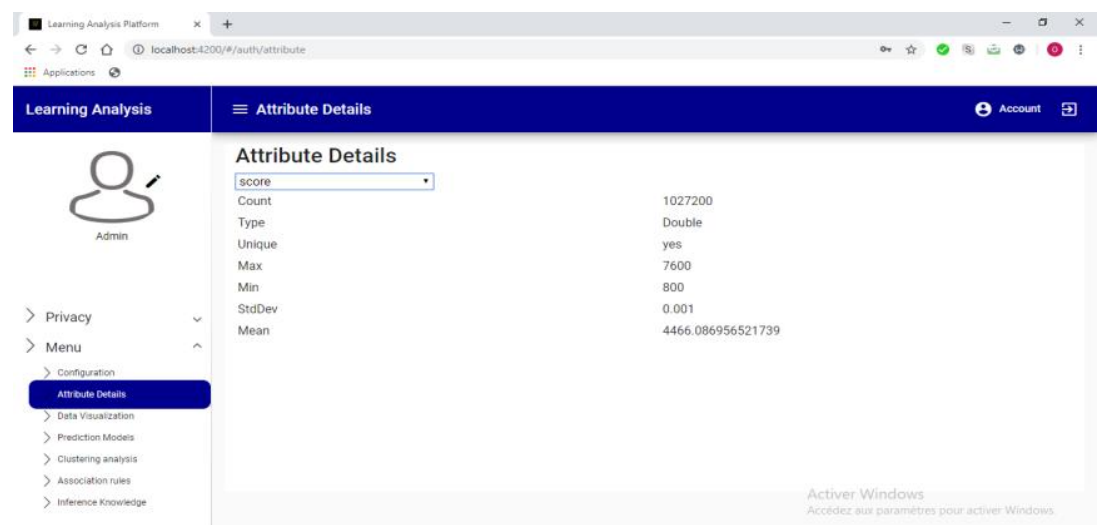

Fig. 10.Summary statistics of the attributes

Among other features of the proposed platform, there are the establishment of predictive models "Figure 11", clustering "Figure 12" and knowledge inference tracing models "Figure 13". To establish predictive models, the user can choose several machine learning algorithms for classification e.g "decision tree, KNN, neural network random forest, etc.", to train the predictive model, after training process he can classify/predict the new data none classified concerning the behaviors of the new learners.

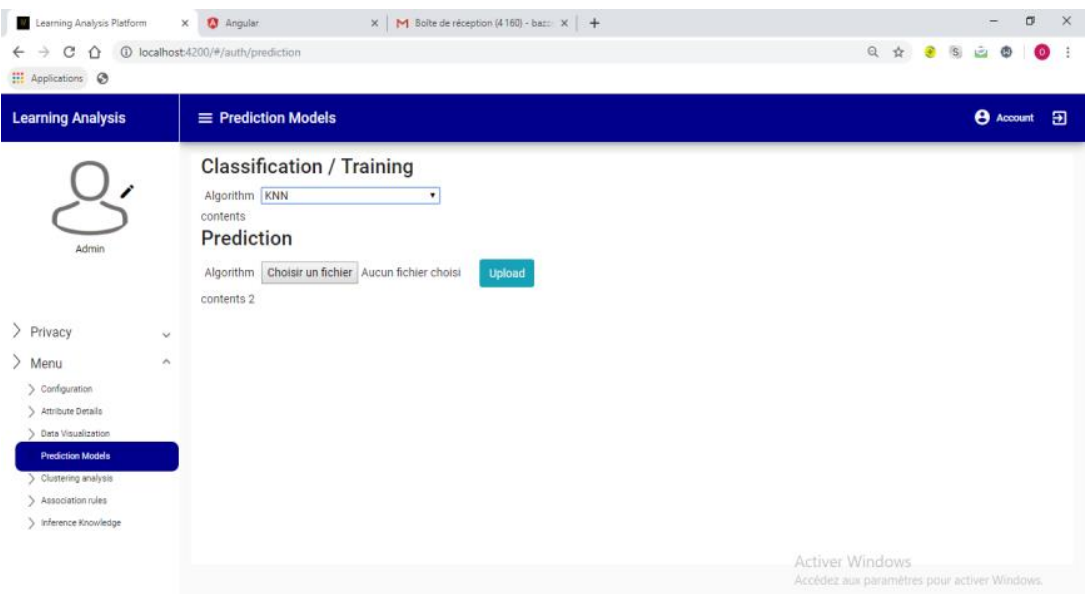

Fig. 11.Process of Classification Training

Concerning the clustering is the same procedure followed in the classification graphical user interface, where the user can also choose the corresponding algorithm "K means, EM, PCA" to do clustering, then he can analyze the clusters obtained after the training process. 


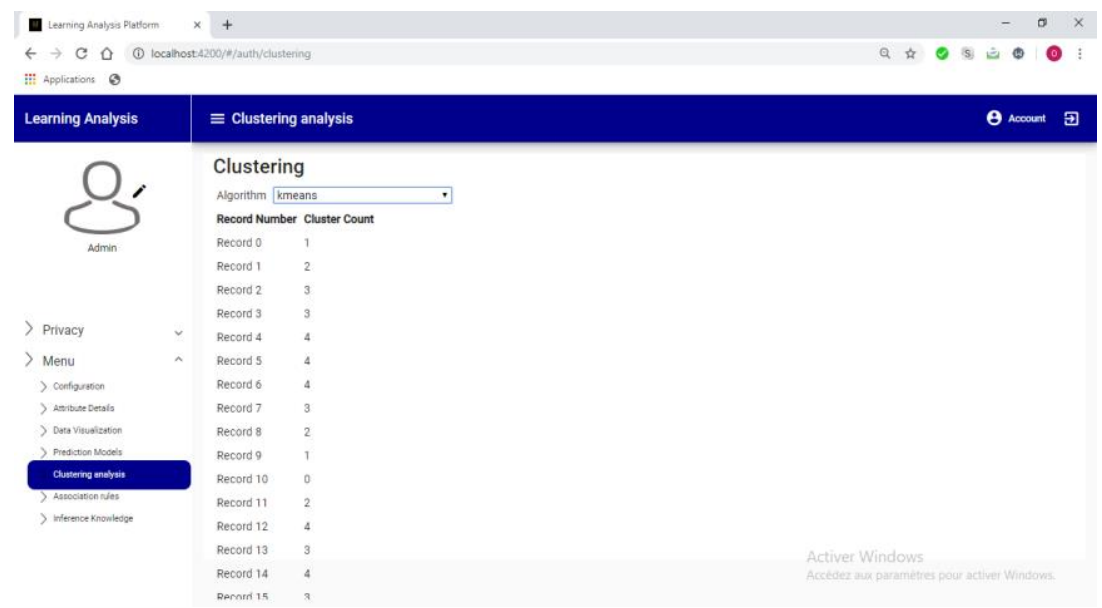

Fig. 12.Process of Clustering Training

The last web interface consists of predicting learners' performances based on BKT parameters were fit by trying every combination of the four BKT parameters Lzero, Guess, Slip, and T on a dataset, and returning the combination which resulted in the best sum of squared residuals (SSR) on predicting the learners' answers, during this step the user should upload a specific log file that contains information about skills, time total actions, right answer of all learners.

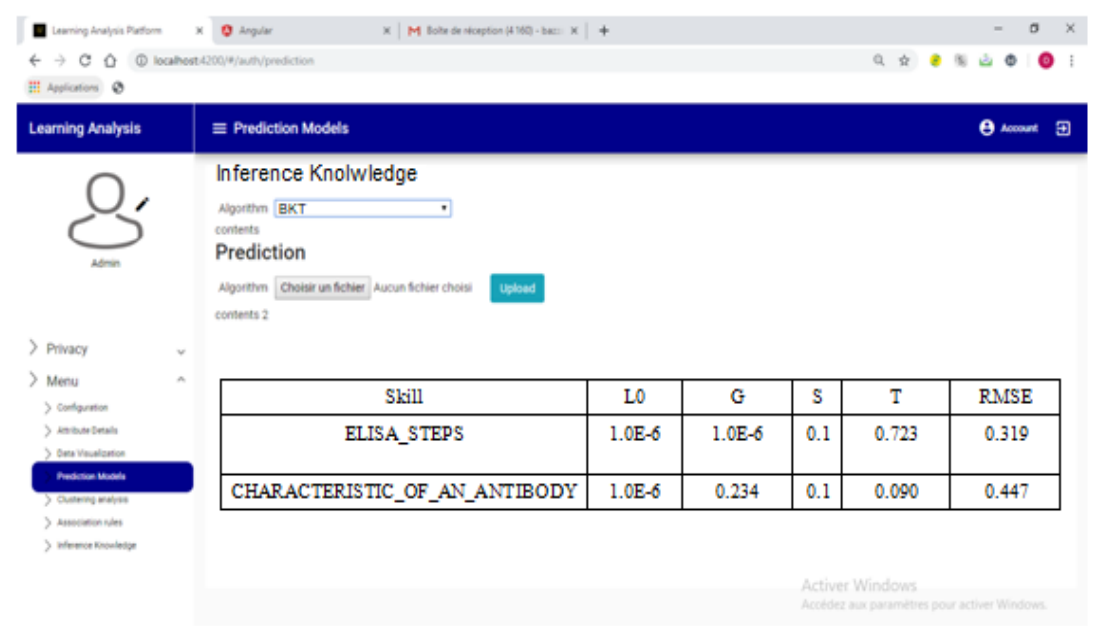

Fig. 13.Process of Bayesian Knowledge Tracing

The idea behind the proposed platform as shown before is offering a user friendly platform to both instructors and teachers, in order, to allow them doing analysis about the learners' progression during a sequence of mobile serious game, the variety of features offed buy the platform offers to users a large possibilities to apply several 
learning analytics technics and algorithms on serious games. Moreover, users can generate their predictive models by using several classification algorithms, they can also generate different inference knowledge models based on the log file uploaded to the platform, and they can also do clustering to analyze and understand the behaviors of learners then propose the solutions according to the obtained results. The platform still a proof of concept it needs more development by adding other algorithms applied in the field of learning analytics like association rules, implementation of others machine learning algorithms, and also inference knowledge algorithms.

\section{Conclusion}

Learning outcomes analysis still a promising research area in the field of smart education generally and serious games especially, during this research work, we have designed and established a platform for learning outcomes analysis dictated for mobile serious games, with a global aim to offer both easy and efficient tool to the instructor, that will help them during the work with learners in order to, acquire new skills. The proposed platform will also allow them to apply more improvements in their teaching manners, in a way to meet the requirements and needs of their learners. The platform still under development and still other features to be added, these features will give the users more flexibility and fluidity when the will use it for their analysis.

\section{References}

[1] O'Shea, T. and Self, J. (1983) Learning and Teaching with Computers, Harvester Press, Brighton.

[2] Crescente, Mary Louise; Lee, Doris (2011). "Critical issues of M-Learning: design models, adoption processes, and future trends". Journal of the Chinese Institute of Industrial Engineers 28 (2): 111-123. https://doi.org/10.1080/10170669.2010.548856

[3] Charsky, D. From Edutainment to Serious Games: A Change in the Use of Game Characteristics. Games Cult. 5, 177-198 (2010). https://doi.org/10.1177/1555412009354727

[4] Phil Wilkinson, A Brief History of Serious Games, book: Entertainment Computing and Serious Games, October (2016). https://doi.org/10.1007/978-3-319-46152-6_2

[5] Unreal Engine 3, www.unreal.com [visited: 17/12/2018].

[6] CryEngine 3, http://www.cryengine.com [visited: 17/12/2018].

[7] Unity Game Engine, http://www.unity3d.com [visited: 17/12/2018].

[8] Sanchez, J., Olivares, R.: Problem-solving and collaboration using mobile serious games. Comput. Educ.57, 1943-1952(2011). https://doi.org/10.1016/j.compedu.2011.04.012

[9] Jarvis, S., de Freitas, S., Evaluation of a Serious Game to support Triage Training: In-game Feedback and its effect on Learning Transfer. Proceedings of 2009 IEEE Conference in Games and Virtual Worlds for Serious Applications, 2009. https://doi.org/10.1109/vs-gam es.2009.31

[10] Karl M, The Gamification of Learning and Instruction: Game-Based Methods and Strategies for Training and Education. San Francisco: Wiley/Pfeiffer (2012). 
[11] Siemens, George. "What Are Learning Analytics?" Elearnspace, August 25, 2010. http://www.elearnspace.org/blog/2010/08/25/what-are-learning-analytics/

[12] Baker, R.S.J.d., Barnes, T. \& Beck, J.E., Proceedings of the 1st International Conference on Educational Data Mining (2008).

[13] Baker, R. S.J.d. \& Yacef, K. (2009). The State of Educational Data Mining in 2009: A Review and Future Visions. Journal of Educational Data Mining, 1(1), 3-17.

[14] Baker, R. S.J.d., Merceron, A. \& Pavlik, P.I. (2010). Proceedings of the 3rd International Conference on Educational Data Mining. Retrieved February 10, 2012, from http://educationaldatamining.org/EDM2010/

[15] Corbett, A.T., Anderson, J.R.: Knowledge tracing: Modeling the acquisition of procedural knowledge. User Modeling and User-Adapted Interaction 4(4), 253-278 (1995). https:// doi.org/10.1007/bf01099821

[16] Utopolis Serious Game, https://utopolisthegame.wordpress.com [visited: 17/12/2018].

[17] Elaachak Lotfi and Bouhorma Mohammed, (2018). Teaching Object-Oriented Programming Concepts through a Mobile Serious Game. In Proceedings of the 3rd International Conference on Smart City Applications (SCA '18), ACM, New York, NY, USA, Article 74, 6 pages. https://doi.org/10.1145/3286606.3286851.

[18] M. Graafland, M. F. Vollebergh, S. M. Lagarde, M. van Haperen, W. a. Bemelman and M. P. Schijven, "A Serious Game Can Be a Valid Method to Train Clinical Decision-Making in Surgery," World J. Surg., vol. 38, no. 12, pp. 3056-3062, 2014. https://doi.org/10.1007/s 00268-014-2743-4

[19] Dr. Game: Surgeon Trouble mobile serious game, http://weirdbeard.nl/lapchol/ [visited: 18/12/2018].

[20] Siemens G, Long P. Penetrating the fog: Analytics in learning and education. Educause Review. 2011; 46(5):30.

[21] Guenaga M, Garaizar P. From Analysis to Improvement: Challenges and Opportunities for Learning Analytics. IEEE Revista Iberoamericana de Tecnologias del Aprendizaje. 2016; 11(3):146-7. https://doi.org/10.1109/rita.2016.2589481.

[22] Chatti MA, Dyckhoff AL, Schroeder U, Thus H. A reference model for learning analytics. Int J Tech Enhanced Learn (IJTEL). 2012; 4 (5/6):318. https://doi.org/10.1504/ijtel.2012.051815.

[23] Clow D. An overview of learning analytics. Teach High Educ. 2013; 18(6):683-95. doi: 10.1080/13562517.2013.827653.

[24] Scheffel, M., Drachsler, H., Stoyanov S., \& Specht, M. (2014). Quality indicators for learning analytics. Educational Technology \& Society, 17(4), 117-132.

[25] C. Romero and S. Ventura "Educational Data Mining: A Review of the State of the Art", IEEE Transactions on Systems Man, and Cybernetics-Part C: Applications and Reviews, Vol. 40, no. 6, November 2010.

[26] Umamaheswari. K, and S. Niraimathi "A Study on Student Data Analysis Using Data Mining Techniques", International Journal of Advanced Research in Computer Science and Software Engineering, Volume 3, Issue 8, ISSN: 2277 128X, August 2013.

[27] E. Osmanbegovic, and M. Suljic "Data Mining Approach for Predicting Student Performance", Economic Review - Journal of Economics and Business, Vol. X, Issue 1, May 2011.

[28] Conati, C., Gertner, A. and Vanlehn, K., 2002. Using Bayesian Networks to Manage Uncertainty in Student Modelling. User Modeling and User-Adapted Interaction 12(4), pages 371-417. https://doi.org/10.1023/a:1021258506583 
[29] Corbett, A.T. and Anderson, J.R., 1995. Knowledge Tracing: Modeling the Acquisition of Procedural Knowledge. User Modeling and User-Adapted Interaction 4(4), pages 253-278. https://doi.org/10.1007/bf01099821

[30] Jastrzembski, T.S, Gluck, K.A. and Gunzelmann, G. Knowledge Tracing and Prediction of Future Trainee Performance. Proceedings of the Interservice/Industry Training, Simulation, and Education Conference, Orlando, Florida, USA, 2006.

[31] Levinson, S.E., Rabiner, L.R., Sondhi, M.M.: An Introduction to the Application of the Theory of Probabilistic Functions of a Markov Process to Automatic Speech Recognition. Bell System Technical Journal 62(4), 1035-1074 (1983). https://doi.org/10.1002/j.15387305.1983.tb03114.x

[32] Baker, R.S.J., Corbett, A.T., Aleven, V.: More Accurate Student Modeling through Contextual Estimation of Slip and Guess Probabilities in Bayesian Knowledge Tracing. In: Woolf, B.P., A“̈meur, E., Nkambou, R., Lajoie, S. (eds.) ITS 2008. LNCS, vol. 5091, pp. 406-415. Springer, Heidelberg (2008). https://doi.org/10.1007/978-3-540-69132-7_44

[33] Taiwo, O. A. (2010). Types of Machine Learning Algorithms, New Advances in Machine Learning, Yagang Zhang (Ed.), ISBN: 978-953-307-034-6, InTech, University of Portsmouth United Kingdom. Pp 3 - 31. Available at InTech open website: http://www.intech open.com/books/new-advances-inmachine-learning/types-of-machine-learning-algorithms. https://doi.org/10.5772/9385

[34] K. Alsabati, S. Ranaka, V. Singh, “An efficient k-means clustering algorithm”, Electrical Engineering and Computer Science, 1997

[35] M. Andrecut, "Parallel GPU Implementation of Iterative PCA Algorithms", Institute of Biocomplexity and Informatics, University of Calgary, Canada, 2008[36] O. Cappe' and E. Moulines. 2009. Online expectation- maximization algorithm for latent data models. Journal of the Royal Statistics Society: Series B (Statistical Methodology), 71. https://doi.org/ 10.1111/j.1467-9868.2009.00698.x

[36] Agrawal R., Imielinksi T., Swami A. Mining association rules between sets of items in a large database, in The ACM SIGMOD Conference, 1993, pp. 207-216. https://doi.org/10. $\underline{1145 / 170036.170072}$

[37] Beatriz Fernández-Gallegoa, Manuel Lama,*, Juan C. Vidala, Manuel Mucientes, Learning Analytics Framework for Educational Virtual Worlds, 2013 International Conference on Virtual and Augmented Reality in Education, Procedia Computer Science 25 ( 2013 ) 443 - 447. https://doi.org/10.1016/j.procs.2013.11.056

[38] Ioannis Kazanidis, Stavros Valsamidis, Theodosios Theodosiou, a Proposed framework for data mining in e-learning: the case of open e-class, 2019 IADIS - International Association for Development of the Information Society, 2019.

[39] Hiroaki OGATA, Rwitajit MAJUMDAR, Gökhan AKÇAPINAR, Mohammad Nehal HASNINE, Brendan FLANAGAN, Beyond Learning Analytics: Framework for Technology-Enhanced Evidence-Based Education and Learning, 26th International Conference on Computers in Education. Philippines: Asia-Pacific Society for Computers in Education, 2018.

[40] DeFreitas, K. and Bernard, M. 2014. A Framework for Flexible Educational Data Mining. Proceedings of the International Conference on Data Mining (DMIN) (2014), 1.

[41] Arham Muslim, Mohamed Amine Chatti, Muhammad Bassim Bashir, Oscal Eduardo Barrios Varela, Ulrik Schroeder, A Modular and Extensible Framework for Open Learning Analytics, Journal of learning analytics, Volume 5(1), $92-100$. http://dx.doi.org/10.18608/jla.2018.51.7, 2018. https://doi.org/10.18608/jla.2018.51.7 
[42] Deborah West and David Heath, Let's Talk Learning Analytics: A Framework for Implementation in Relation to Student Retention, Online Learning - Volume 20 Issue 2 - June 2016. https://doi.org/10.24059/olj.v20i2.792

[43] Angelo F. Dias et al, Development of a Data Mining Education Framework for Data Visualization in Distance Learning Environments, the 29th International Conference on Software Engineering \& Knowledge Engineering, Wyndham Pittsburgh University Center, Pittsburgh, USA, 2017, DOI reference number: 10.18293/SEKE2017-130.

[44] Renien John Joseph, SINGLE PAGE APPLICATION AND CANVAS DRAWING, International Journal of Web \& Semantic Technology (IJWesT) Vol.6, No.1, January 2015. https://doi.org/10.5121/ijwest.2015.6103

[45] R. Fielding. Architectural Styles and The Design of Network-based Software Architectures. $\mathrm{Ph} . \mathrm{D}$. thesis, University of California, Irvine, 2000.

[46] S. Vinoski. Putting the "Web" into Web services: Interaction models, part 1: Current practice. IEEE Internet Computing, 6(3):89-91, May-June 2002. https://doi.org/10.1109/mic. $\underline{2002.1020331}$

[47] Eibe Frank et al, The WEKA Data Mining Software: An Update, SIGKDD Explorations Volume 11, Issue 1, April 2000.

[48] Abdelali Slimani, Fatiha Elouaai, Lotfi Elaachak, Othman Bakkali Yedri, Mohammed Bouhorma, Mateu Sbert: Learning Analytics Through Serious Games: Data Mining Algorithms for Performance Measurement and Improvement Purposes. IJET 13(1): 4664 (2018). https://doi.org/10.3991/ijet.v13i01.7518

\section{$7 \quad$ Author}

Elaachak Lotfi is assistance professor in Abdelmalek Essadi University, Faculty of Sciences and Technologies of Tangier, Morocco. His recent research and policy interests concentrate broadly in the area of serious game, e-learning learning analytics, web marketing and augmented reality.

Article submitted 2019-09-07. Resubmitted 2019-10-05. Final acceptance 2019-10-05. Final version published as submitted by the authors. 